\title{
O Político, o Público e a Alteridade Como Desafios para a Psicologia
}

Resumo: A idéia central do ensaio é que é necessário incluir a dimensão política na formação em Psicologia, na qual predomina um enfoque individualista, que mantém o sistema de desigualdade, impedindo o desenvolvimento da pluralidade e o ideal de bem comum. Questóes de raça e etnia e outras diferenças devem ser tratadas juntamente com a questão do racismo. A autora fundamenta seu argumento a partir de sua experiência como professora do Departamento de Psicologia da Universidade Federal de Minas Cerais, onde adota o grupo operativo como metodologia de ensino, considerando as relações de poder que se estabelecem no grupo.

Palavras-Chave: Política, racismo, pluralidade, grupo operativo.

Abstract:The central idea of this essay is that it is necessary to include the political dimension in the study of Psychology, since the individualism that characterizes this discipline helps to maintain inequality and functions as an obstacle to plurality and the ideal of common good. Questions of race and ethnicity must be dealt with the question of racism. The author bases her argument in her own experience as a professor of Social Psychology in a public university, where she adopts Pichon-Rivière's technique of Operative Group as a teaching methodology, considering the power relations in the group.

Key Words: Political, racism, plurality, operative group.
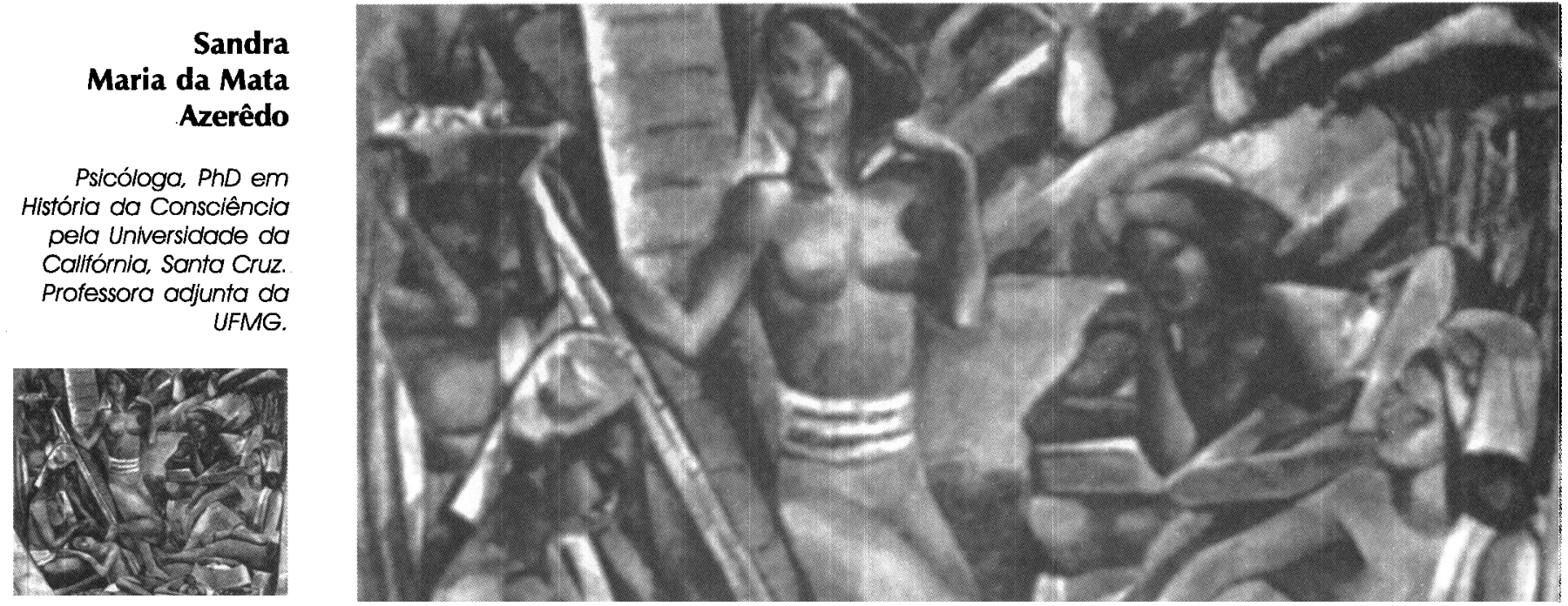

\section{O Cotidiano das Relações Raciais no Brasil}

A filha de 3 anos de um casal de amigos meus, que são negros, diz que quando ela crescer vai ser branca. Uma mulher negra do nosso grupo na Delegacia de Mulheres de Belo Horizonte diz que seus lábios são grossos demais para ela deixar a marca de sua boca no cartaz que produzimos juntas para convidar outras mulheres para o grupo. deixemos nossa marca no cartaz. Outra mulher no grupo -também negra-comenta um dia que a amante do marido é italiana, sugerindo que isso torna maior sua dor de ser traída. Essa mesma mulher, antes de me ver, tinha a expectativa de que eu, a psicóloga da UFMG, responsável pelo grupo -e, portanto, numa posição de autoridadefosse "mais clarinha" do que na verdade sou. Outro dia, de manhã, a caminho da universidade, ao 
passar de ônibus pela Praça da Rodoviária, vi uma porção de policiais revistando um jovem negro sem camisa, algemado, encostado na parede, que chorava desesperado, falando sem parar. Lembrei-me da música de Caetano Veloso e Gilberto Gil, "Haiti", que diz que "presos são quase todos pretos ou quase pretos, ou quase brancos quase pretos de tão pobres e pobres são como podres e todos sabem como se tratam os pretos". E nunca me esqueço de uma música de Carnaval que eu cantava quando era menina, que dizia:

No Japão é que é bom/ Japonês não passa mal/ Não há mulher bonita/ Nem feia, é tudo igual/ Não há lourinha/ Não há, não há, não há.../ Morena, nem pretinha/ Nem mulata sarará./ Lá não se briga/ Por causa de mulher/ Quem perde a sua/ Apanha a que quiser.

$\mathrm{E}$, certamente, também me lembro da outra música -muito conhecida-que fala que, já que "a cor não pega", é possível desejar o amor da mulata, cujo cabelo não nega sua cor, que é uma invenção brasileira.

Inicio este ensaio com alguns exemplos de minha experiência cotidiana aqui no Brasil porque todos eles se referem a diferenças de etnia, raça e/ou cor. Como se pode ver em todos os exemplos, raça, etnia e cor, pelo menos no Brasil, não são termos inocentes, e muito menos neutros: a menininha negra quer ser branca, a mulher negra acha seus lábios grossos demais, a outra mulher negra tem ciúmes da "italiana" e esperava que a psicóloga fosse mais clara do que realmente é, o rapaz que está sendo revistado pela polícia é negro, como quase todos os presos e os pobres, e as letras de música de carnaval indicam uma complexa interrelação da raça/etnia/cor com sexo ao tratar as mulheres como, ou sendo "tudo igual", ou sendo classificadas como louras, morenas, mulatas, que podem ser escolhidas como se escolhe uma mercadoria na prateleira. Os anúncios -de cerveja ou de carro-especialmente dirigidos aos homens ${ }^{2}$, utilizam claramente essa equiparação da mulher com a mercadoria que está sendo anunciada. E a mulata é uma fabricação nacional, quem a deseja não corre perigo de "pegar" sua cor escura, como quem "pega" uma doença. E, além de mulatas, também se fabricam louras e morenas no Brasil, como aconteceu no concurso nacional para escolher quem iria substituir uma das integrantes do conjunto de música Tchan ${ }^{3}$. Nessa fabricação, as candidatas têm que se enquadrar em medidas físicas padronizadas e têm que cumprir uma série de exigências, sendo o cabelo longo uma das mais importantes. Como na música, aqui no Brasil o cabelo parece ser realmente um indicador da raça/cor da pessoa. Temos várias expressões para designar o cabelo das pessoas, especialmente o das pessoas negras cabelo duro, cabelo pixaim, cabelo encarapinhado, carapinha, cabelo de negro, que se opōem ao "cabelo sedoso" das brancas. Há, inclusive, uma série de produtos para alisamento, ou mesmo "relaxamento" para os "cabelos de negro", que, curiosamente, se denominam "produtos étnicos". Além disso, o cabelo longo parece ser um importante item para indicar a feminilidade de uma mulher.

\section{O Desafio da Pluralidade Étnica para a Psicologia}

As relaçōes raciais no Brasil tornam-se ainda mais complexas pelo fato de acontecerem em um contexto de extrema desigualdade, onde, paradoxalmente, domina uma ideologia de "democracia racial", cuja expressão mais comum é a afirmação de que todo mundo no Brasil tem "um pé na cozinha", inclusive o presidente, como ele mesmo declarou certa vez. Por isso, falar de "pluralidade étnica" aqui torna-se um desafio, sobretudo para a Psicologia, uma disciplina que tem privilegiado o enfoque individualista, não prestando atenção às determinações históricas nem tampouco à dimensão política da constituição do ser humano. Seguindo Hannah Arendt, entendo essa dimensão política como se referindo à "ação política, [que,] como toda ação, é sempre essencialmente o começo de algo novo; como tal, ela é ... a própria essência da liberdade humana" (1993: 51). Para Arendt, a ação "corresponde à condição humana da pluralidade", e "esta pluralidade é especificamente a condição de toda vida política" (1987: 15). Porém, o que considero mais importante para pensarmos sobre as relações raciais no Brasil é que Arendt enfatiza que a pluralidade humana está intimamente associada à singularidade. "A pluralidade é a condição da ação humana pelo fato de sermos todos os mesmos, isto é, humanos, sem que ninguém seja exatamente igual a qualquer pessoa que tenha existido, exista ou venha a existir" (1987: 16). Numa sociedade que trata as pessoas como mercadorias, produzidas em série, é difícil falar em singularidade e, portanto, é difícil falar em pluralidade. Michel Foucault aponta para o problema da objetificação que transforma seres humanos em sujeitos, dividindoos e separando-os dos demais e de si mesmos (1983: 208), isto é, os sujeitos não se reconhecem como humanos, iguais e diferentes, na pluralidade e na singularidade.

O enfoque individualista que tem sido geralmente privilegiado pela Psicologia está em sintonia com a sociedade desigual que tem sido o Brasil desde o tempo da colônia, e considero que permanecer nesse enfoque significa compactuar com o processo que produz a desigualdade. ...é que numa rua do Rlo de Janeiro

peguei no ar de

relance o sentimento de perdição no rosto de uma moça nordestina. (...)A

moça é uma verdade da qual eu nõo queria saber

Clarice Lispector,

A Hora da Estrela.

E eu pergunto aos economistas políticos, aos moralistas, sejá calcularamo número de individuos que é forçoso condenar à miséria, ao trabalho desproporcionado, à desmoralização, à

infância, ò

ignorância

crapulosa à desgraça invencível, à penúria absoluta. para produzir um rico.

Almeida Garrete, citado em José Saramago, Levantados do Chăo.

Dans cette humanité centrale et centralisée, effect et instrument de relations de pouvoir complexes, corps et forces assujettis par des dispositifs d" "incarcération" multiples, objets pour des discours qui sont eux-mêmes des éléments de cette strotégie, il fout entendre le grondement de la bataille.

Michell Foucault, Surveiller et Punir' 
1 Nesta humanidade central e centralizada, efeito $e$ instrumento de relaçōes de poder complexas, corpos e forças assujeitado por dispositivos múltiplo de "encarceramento". objetos para discursos que são eles próprios elementos dessa estratégia, é preciso escutar o rugido da batalha. M. Foucault, Vigiar e Punir

$2 \mathrm{~A}$ bebida alcóolica é uma das formas de demonstrar virilidade entre os adolescentes do sexo masculino e carro -e outros veiculos motonzados - ainda säo brinquedos obrigatórios para os meninos, assim como a boneca o é para as meninas.

3 Thhan éo nome de um conjunto muito conhecido no Brasil composto por vários homens negros e apenas duas mulheres. No inicio. havia uma loura $e$ uma negra/mulata. E, depois do concurso da "Morena do Tchan". a negra foi substituida por uma morena -de cabelos lisos. Mais tarde, houve um concurso da "loura do Tthan", que substituiu a primeira loura do conjunto.

4 Ver a este respeito a excelente entrevista de Ana Bock. presidente do CFP, na Veja (26/ 04/2000) sobre a "Guerra ao Preconceito". E também os números da revista do CFP, que incentivam publicaçōes voltadas para questöes sociais e politicas. A própria instituição do prêmio Arthur Ramos com o objetivo de estimular a produção sobre a questão da pluralidade étnica na Psicologia é indicativa deste empenho da disciplina em se transformar no sentido de combater desigualdades no Brasil.
Em seu trabalho sobre negros e negras pobres em Belo Horizonte, José Tiago Reis Filho estranha que, "tendo como um dos seus pilares a construçāo da identidade, a Psicologia dispo[nha] de tão poucos meios para falar da questão racial" (2000: 21). Concordo com Reis Filho e, acredito, como Michelle Rosaldo, que, se o que sabemos agora sobre essa questão esteja restringido pelas estruturas de interpretação que limitam nossos pensamentos, "o que podemos saber será determinado pelo tipo de questões que aprendemos a fazer" (1995: 13). Ao invés de ter mais dados, precisamos, então, aprender a levantar as questōes que poderão abrir caminhos para resolvermos os enormes problemas do racismo e sua complexa relação com outras formas de dominação e exploração. Precisamos fazer perguntas e também, o que é muito importante, aprender a escutar as respostas, com ouvidos abertos para a diferença. Esse me parece ser o grande desafio da Psicologia neste início de século. Escutar o outro, pegar no ar o sentimento de perdição no rosto dos excluídos, mesmo que "de relance", como fez Clarice com Macabéa. Enfim, escutar "o rugido da batalha", como nos propõe Foucault. É preciso querer saber das verdades do outro e não ficarmos presos à mesmice de nossas verdades, tantas vezes apoiadas em privilégios.

Neste ensaio, levanto algumas questões do ponto de vista da formação de profissionais em Psicologia partindo de minha experiência como professora da disciplina Psicologia Social II no Departamento de Psicologia da FAFICH, UFMG. Meu argumento é que essa formação tem basicamente ignorado a dimensão política do que constitui o objeto principal da Psicologia, que é a construção do sujeito humano com uma identidade sexual, étnica/racial, e de classe. Vejo o desafio da Psicologia, portanto, como sendo o de criar condições de nos abrirmos para a diversidade de identidades étnicas, de parcerias sexuais, de modos de ser sexuados, de experiências de classe, de idade, de religião, etc., de modo a buscarmos soluçōes coletivas para resolver o problema da desigualdade. Esse desafio tem sido aceito dentro da Psicologia no Brasil já há algum tempo se pensamos, por exemplo, na criação da Associação Brasileira de Psicologia Social/ABRAPSO, cujo objetivo foi precisamente o de se contrapor a um domínio da Psicologia Social americana, cuja visão do social se limitava a pequenos grupos, sem a menor consideração do contexto histórico. Também, mais recentemente, o próprio Conselho Federal de Psicologia tem assumido boas posições em relação à diferença. ${ }^{4}$ No entanto, há ainda muito a fazer, especialmente pelo fato de estarmos vivendo agora num mundo globalizado, onde os meios de comunicação de massa, sobretudo a televisão e a internet, passaram a desempenhar um papel crucial.
Dessa forma, considero que o desafio à Psicologia brasileira não seja apenas a pluralidade étnica, ou pelo menos, ainda não seja a pluralidade étnica, tendo em vista a desconsideração que ainda existe da própria pluralidade, que possibilita a ação política, que transforma o sujeito e o mundo. Acredito que o grande desafio, na verdade, seja introduzir o político na nossa formação. Acredito que a introdução do político na formação em Psicologia significa não apenas trabalhar dentro de uma perspectiva da área de Psicologia Política, que, certamente, é de fundamental importância na nossa formação, conforme atesta o primeiro número da revista Psicologia Política, que contém dois artigos sobre a questão do racismo no Brasil, o artigo de Leôncio Camino e o de Maria Palmira da Silva. Na medida em que estamos considerando o político como relacionado com a pluralidade, a diversidade e as relações de poder que aí se estabelecem, sua introdução na formação em Psicologia significa, sobretudo, possibilitar a passagem proposta por Suely Rolnik entre o afeto e a representação para chegarmos a uma nova prática do pensamento que acolha e encarne a diferença. Para ela, "abrir-se para a alteridade ... é abrir-se para a virtual diferenciação engendrada no encontro com o outro, tornar-se um veículo de atualização dessa diferença, um veículo de criação de novos modos de subjetivação, novos modos de existência, novos tipos de sociedade" (1994: 172).

Uma recente reportagem da revista Veja -a revista de maior circulação no País-sobre "miséria, o grande desafio do Brasil" (de 23/01/2002) constitui um bom exemplo do enfoque individualista que faz parte do contexto da formação em Psicologia. A capa da revista mostra dois meninos pobres -um deles negro-deitados numa esteira no chão. E no artigo de Ricardo Mendonça intitulado "O Paradoxo da Miséria", há três chamadas que apontam para a questão da diversidade de etnias no Brasil:

o primeiro contingente de miseráveis surgido no país foram os escravos. Mesmo depois da Abolição, eles continuaram vivendo numa situação de pobreza extrema. Essa herança reflete-se até hoje em estatísticas como as taxas de analfabetismo e de mortalidade infantil, proporcionalmente maiores entre a população negra (2002: 93).

As minorias também estão entre as principais vítimas da miséria. Na região do município de Dourados, em Mato Grosso do Sul, 9000 índios vivem em condições de extrema pobreza (93).

Metade dos miseráveis brasileiros vive no Nordeste, geralmente na zona rural de cidades muito pequenas. Nesses bolsōes de pobreza assolados pela seca, falta comida e não há trabalho para todo mundo (82). 
Negros/escravos, indios/minorias e nordestinos/ miseráveis. No início do século XXI, já não podemos tratar da questão da pluralidade étnica sem tratar também do racismo que nos assombra desde a época do colonialismo e que tem uma complexa relação com o sexismo e a exploração de classe. Porém, a ênfase do artigo de Veja não é no desafio colocado pela miséria que atinge principalmente determinados grupos étnicos, tornando explícito o racismo. Essa questão não é sequer colocada. Ao invés disso, o artigo apela, por um lado, para o assistencialismo e, por outro lado, para o desempenho da economia, tentando fazer uma aliança entre esses dois elementos, aliança sempre perversa por impedir a agência e a criatividade dos sujeitos na solução de seus problemas, sufocando assim qualquer resistência à dominação e à exploração. Segundo o artigo, "nunca se gastou tanto dinheiro na área social". A Comunidade Solidária, que é considerada pelo artigo "uma façanha" realizada pelo governo, juntou "um exército de voluntários que já conta com mais de 20 milhões de pessoas [que] ajudam a tornar menos sofrida a vida de doentes, menores e idosos abandonados e os miseráveis. Infelizmente, tal apoio não basta para reverter os indicadores sociais," lamenta o artigo, e coloca uma pergunta retórica, "Por quê?" E a resposta vai ser buscada apenas no desempenho da economia. O plano real é considerado no artigo como sendo "uma das maiores realizações do presidente Fernando Henrique Cardoso". E, em seu "período inicial", é visto como "uma singela exceção" no processo de acumulação de riqueza nas mãos de poucos em detrimento da grande maioria da população, que vem acontecendo desde o início da História do Brasil, pois "milhões de pobres se beneficiaram do fim do imposto inflacionário e passaram a ter renda mínima para a sobrevivência" (93). Ou seja, o plano real possibilitaria mobilidade social, que viria do "bom desempenho econômico do País", porém, segundo o artigo, seria preciso concentrar "as despesas no ensino básico e deixar de lado os gastos com as universidade federais". A mensagem central do artigo é essa intenção de "deixar de lado" a universidade pública, como se deixou de lado na década de sessenta o ensino público de segundo grau.

Diante dessa calamidade proposta pelo artigo da revista de maior tiragem do País, é urgente levantarmos questões sobre o por quê dessa concentração de grupos específicos -negros, índios e nordestinos-nas faixas mais pobres. E é justamente no ensino público que essas questões precisam ser levantadas. Por que? Porque, como argumenta Arendt, o sentido de público se acha justamente na pluralidade, no encontro de seres humanos que são diferentes e ao mesmo tempo iguais. É a partir dessa pluralidade baseada em nossa singularidade que podemos construir uma democracia que tenha uma preocupação com o bem comum, que não se contente com o mero cumprimento da lei e a não- interferência no direito dos outros. Esse, como escreve Chantal Mouffe, é

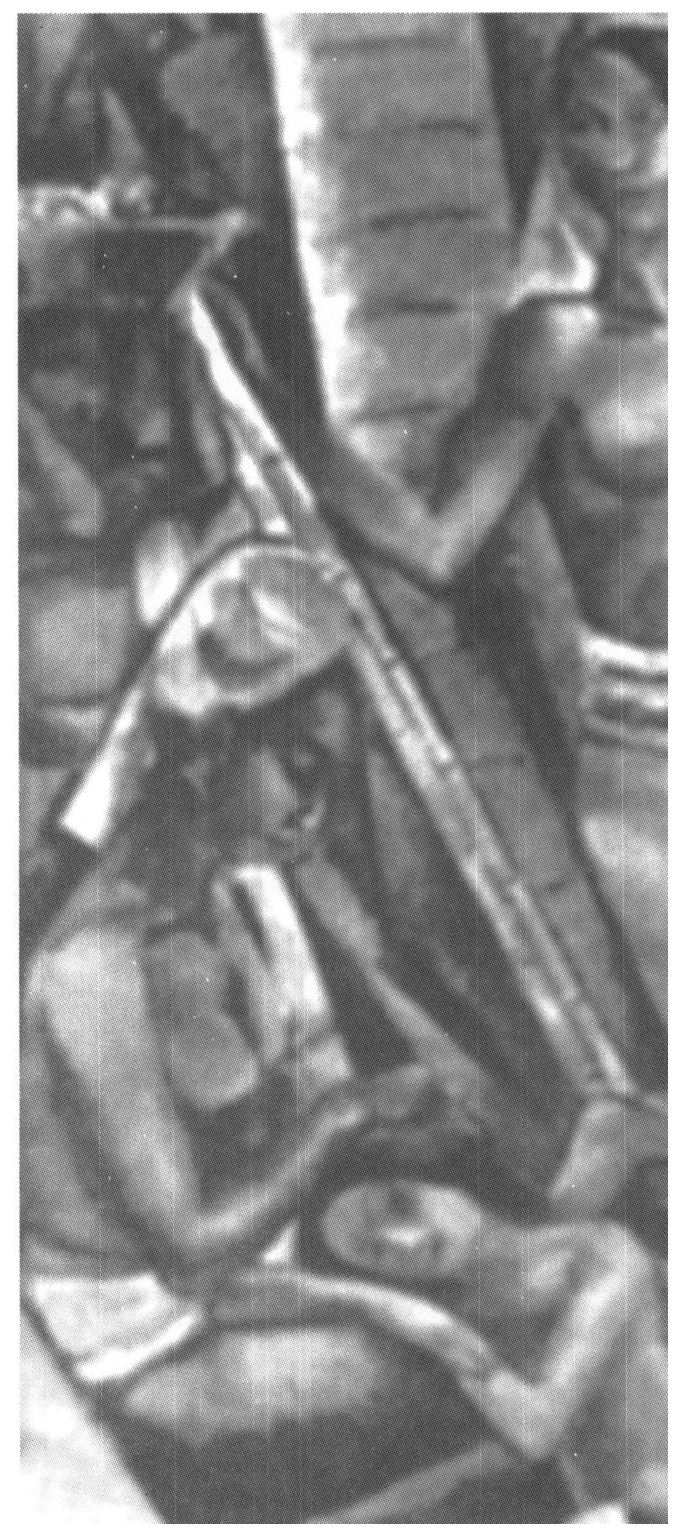

um projeto de "democracia radical e plural", em que se cria uma articulação entre demandas de mulheres, negros/as, operárias/os, homossexuais, e outros. Trata-se de um projeto de democracia que se opõe ao sentido que a democracia tem no Liberalismo - "uma democracia que não dá importância ao espírito público, à atividade cívica e à participação política na comunidade de iguais", como escreve Mouffe.

Hoje, a educação pública secundária no Brasil está inteiramente dizimada e nossos filhos tiveram

\section{"oprimeiro contingente de miseróveis surgido no pais foram os escronos. Mesmo depois da Abolição, eles continuaram vivendo numa situação de pobreza extrema. Essa herança reflete-se até hoje em estatísticas como as taxas de analfabetismo e de mortalidade infantil, proporcionalmente maiores entre a população negra".}

Ricardo Mendonça 
que estudar em escolas particulares, onde não encontraram o mesmo espírito de comunidade livre e aberta das escolas públicas, simplesmente porque seus colegas vinham apenas das classes privilegiadas. Foram estes/as estudantes que passaram a competir com os/as da escola pública - sucateada - para entrar na Universidade. E esse processo injusto se reflete na pouca diversidade da população da universidade pública. E agora a universidade está sofrendo o mesmo processo do segundo grau -0 que se pretende é estimular a privatização da educação superior também. A começar pelos cursos da Graduação.

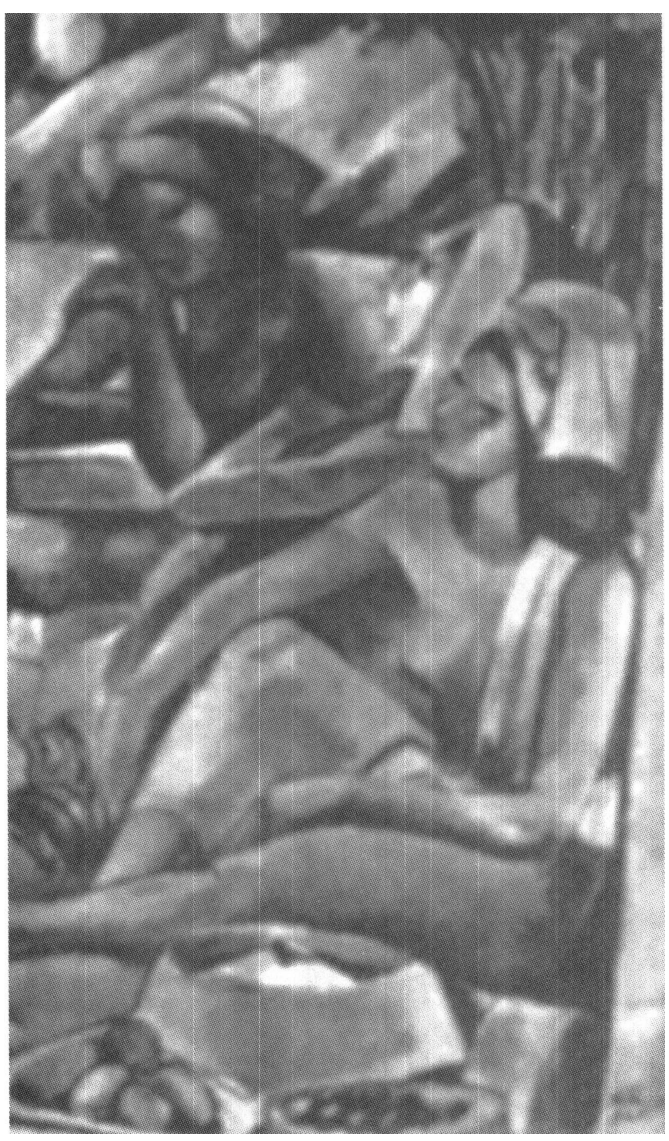

5 Nossa produção é computada de modo a nos distribuir em categorias e niveis -de $1 \mathrm{~A}$ a $2 \mathrm{C}$-como indica o ultimo relatório da Comissão de Seleçāo de Bolsas de Produtividade em Pesquisa do CNPq. Conforme o relatório o primeiro grupo, por exemplo, apresenta uma produção total média de 30,2 itens nos últimos 6 anos, enquanto o último grupo apresenta uma produçăo média de 12,5 itens no mesmo periodo. Além disso, no primeiro grupo, a média do tempo em que o pesquisador nāo apresenta qualquer produção é de 0,57 anos, enquanto no último grupo esta média passa a ser 1,68 anos. Compreendo que essa quantificação seja necessária para se buscar critérios mais objetivos de distribuiçāo das bolsas, que são escassas, porém nāo posso negar que incomoda ver nossa produçao reduzida a números desta forma. a leitura). E, por outro lado, com o desmantelamento do segundo grau, na Graduação os problemas com a escrita e a leitura (e às vezes até com o hábito do pensamento) são quase a regra.

Sinto uma falta enorme de uma comunidade na Universidade -estamos todos/as pulverizados/as, cada um/a em sua sala, preocupados/as em manter a GED, na atualização do Lattes, pensando em qual revista indexada vamos publicar, o que em si seria até positivo se estivéssemos pensando apenas em compartilhar nosso trabalho com a comunidade científica. O problema é que, na atual situação de gradual ruína do espaço de produção do conhecimento -público, livre, político, associado à transformação da sociedade em prol do bem comum - esse conhecimento está aliado aos valores do mercado, à propriedade privada, à produção com vistas apenas a ascender na carreira, à burocratização, enfim. ${ }^{5} \mathrm{Na}$ maioria das vezes estamos pensando apenas em cada um/a de nós individualmente. Simplesmente não temos tempo para nos reunirmos e conversarmos sobre questōes importantes, antes de mais nada porque não nos sentimos pertencendo a uma instituição, a uma comunidade que tem como ideal o bem-estar de todo mundo. Certamente trata-se de um problema global, maior que a UFMG e mesmo o Brasil, porém são necessárias ações locais, a lém de ações globais.

Escrevendo sobre a globalização, Zygmunt Bauman estabelece uma relação importante entre os "globalizados e os locais" para entendermos a situação mundial de desigualdade entre os que podem (ou podiam) desfrutar de uma democracia e segurança e os que estão cotidianamente enfrentando o pesadelo de viver com total insegurança num ambiente de violência e miséria. Além disso, ele mostra que as desigualdades não são meramente econômicas, mas apóiam-se num profundo racismo e sexismo que alimentam a "criação e anulação de estranhos", do outro, do diferente, do homem rico, branco, heterossexual, ocidental. E é aí que entra "o fator Deus", de que nos fala Saramago em um artigo para a Folha de São Paulo logo depois do dia 11 de setembro de 2001, comentando a destruição do World Trade Center em Nova York. Saramago escreve que esse fator se acha tanto na carta do terrorista encorajando-o para o ato de matança, como nas notas de dólar, reafirmando a confiança do povo americano em Deus. Para Bauman, o fator Deus significa um e único, a busca da verdade única (que, para ele, é um pleonasmo) e, portanto, a morte da liberdade, palavra que tem muitos significados, como nos mostra Cecília Meireles no Romanceiro da Inconfidência -não há ninguém que explique nem ninguém que não entenda. Porém, a liberdade não sobrevive ao um e único. Bauman escreve que 
ser livre significa acreditar em muitas coisas demasiadas para a comodidade espiritual de obediência cega: significa estar consciente de que há demasiadas crenças igualmente importantes e convincentes para a adoção de uma atitude descuidada e nihilista ante a tarefa da escolha responsável entre elas; e saber que nenhuma escolha deixaria o escolhedor livre da responsabilidade pelas suas conseqüências. (...)

A voz da consciência - a voz da responsabilidadeé audível, por assim dizer, só no tumulto de melodias não-coordenadas. $O$ consenso e a unanimidade prenunciam a tranqüilidade do cemitério (...); é no cemitério do consenso universal que a responsabilidade, a liberdade e o indivíduo exalam seu último suspiro.

A voz da responsabilidade é o grito de recém-nascido do indivíduo humano. Não necessariamente, porém, é sinal de uma vida feliz -se a felicidade significa ausência de inquietação (por certo, uma definição altamente discutível, embora largamente difundida, de felicidade). A aceitação da responsabilidade não aparece facilmente não exatamente porque ela leva aos suplícios da escolha (...), mas também porque ela anuncia a permanente ansiedade de estar-quem sabe? - errando (1998: 249).

Essa longa citação ajuda a entender o problema da imposição de um pensamento único, que estamos vivendo hoje na universidade e fora dela. Bauman argumenta que a criação de uma comunidade política viável terá que se apoiar justamente no tripé da liberdade, diferença e solidariedade, pois "sem solidariedade... nenhuma liberdade é segura, enquanto as diferenças, e o tipo de 'política de identidade' que elas tendem a estimular, ... de um modo geral terminam na internacionalização da opressão" (1998: 256). Como diz Saramago em seu artigo para a folha, precisamos lutar pelo "mais humano dos direitos: o direito a dizer não, o direito à heresia, o direito a escolher outra coisa, que isso só a palavra heresia significa". Ou, como diz Donna Haraway, agora, "trata-se do sonho não de uma linguagem comum, mas de uma poderosa e herética heteroglossia" (2000: 108).

\section{O Grupo Operativo no Ensino da Psicologia Social}

O sonho de uma poderosa e herética heteroglossia é justamente o que estou pretendendo realizar quando me inspiro na técnica do grupo operativo, de Enrique Pichón-Rivière, para criar uma metodologia de ensino que possibilite a expressão da diversidade e o restabelecimento da pluralidade no sentido que lhe dá Arendt, isto é, no sentido de ser a pluralidade a condição de toda vida política e o sentido da ação política constituir "a própria essência da liberdade humana" por ser o começo do novo, do imprevisível, em oposição ao estereótipo. $\mathrm{O}$ grupo se opõe à série, como mostra Sartre. Ele se define pelo ato, criando uma fusão entre as pessoas.

Silvia Lane argumenta que "só é grupo quando ao se produzir algo se desenvolvem e se transformam as relações entre os membros do grupo, ou seja, o grupo se produz" (1989: 97). Lane chama de nāogrupo (que ela identifica à serialidade de Sartre) as situações em que as pessoas estão reunidas "agrupadas"--porém cada uma fazendo algum tipo de trabalho, sem relação com os demais trabalhos. Para Lane, nessas situações, as relações entre as pessoas não se alteram, como aconteceria numa situação de grupo. Para que se chegue a essa situação, é preciso que o grupo se processe, "superando contradições até se tornar condição de conscientização de seus membros e, consequentemente, agentes históricos" (1989: 95).

A abordagem de Pichon-Rivière também considera a "análise sistemática das contradições" como sendo "uma das tarefas fundamentais do grupo operativo e de toda investigação social" (1994: 127). Porém, Lane faz uma severa crítica a PichonRivière por considerar que ele não estabelece "nenhuma relação ... com a contradição fundamental das condiçōes históricas da sociedade onde o grupo se insere" (1989: 94). Além disso, Lane critica sua busca de interpretação de aspectos inconscientes que interferem no processo grupal, considerando que essa busca torna "o papel do coordenador como dono de um saber que o permite interpretar o psíquico oculto de cada indivíduo" (1989: 94).

Para mim, um dos principais aspectos do grupo operativo é justamente operar no contexto social buscando transformar através da análise de aspectos inconscientes, especialmente dos dois medos básicos que aparecem frente à mudança o medo da perda do conhecido, que PichónRivière chama de ansiedade depressiva, e o medo do ataque do novo, que ele chama de ansiedade paranóide. Esses medos aparecem sobretudo ao estimularmos os aspectos de heterogeneidade do grupo, ou seja, ao tentarmos combater o estereótipo, valorizando a singularidade e a criatividade de cada uma das pessoas que participam de um objetivo comum, que é a realização da tarefa de aprendizagem dos conceitos da ementa da disciplina (conceito de identidade e interação social).

No final de cada grupo, produzimos uma avaliaçāo final, em forma de relatório. ' Cada turma tem uma história particular, com detalhes importantes que
6 Estou também utilizando a técnica de Pichón-Rivière para desenvolver uma forma de atendimento em grupo a mulheres na Delegacia de Mulheres, procurando fazer emergir demandas sociais que levem essas mulheres a agirem como sujeitos e não apenas como vitimas, que se queixam elou fazem uma denúncia contra os companheiros. Para mais informacöes sobre este trabalho. ver meu artigo, o significado da Violência de Gênero $e$ a Questão da Demanda na Delegacia de Mulheres de Belo Horizonte, no Caderno de Debates Plural, março 2001.

7 Ver o primeiro relatório publicado em forma de artigo nos Cadernos de Psicologia da UFMG (1997). 
a marcam como diferente. Há também aspectos que se repetem em quase todos os grupos. Na história dessa última turma, que teve início em agosto de 2001, e, portanto, está sofrendo os efeitos de nossa greve de mais de 100 dias, a questão da aceitação ou rejeição da diferença foi particularmente premente e acredito que nossa dificuldade com a diferença tenha a ver justamente com nosso medo da liberdade, que aparece como o medo da mudança, e que, de certa forma, tem perpassado todas as turmas. Na capa do relatório de avaliação que escrevi para a turma do semestre 2/1997, coloquei um texto de Clarice Lispector que falava desse nosso medo da liberdade. Em um certo trecho, ela escreve: "Assusta a visão talvez irremediável e que talvez seja a da liberdade. $\mathrm{O}$ hábito que temos de olhar através das grades da prisão, o conforto que traz segurar com as duas mãos as barras frias de ferro". Acredito que o problema do encontro com a diferença possa surgir especialmente aí porque, para que haja diversidade, é preciso que cada pessoa se posicione, mostre em que consiste sua singularidade no grupo. E o posicionamento vai se dar num contexto de relações de poder e, portanto, de resistência.

\section{A verdade é deste mundo; elaé produzida nele graças a múltiplas coerções enele produz efeltos regulamentados de poder(...) Há um combate "pela verdade" ou, ao menos, "em torno da verdade".}

Foucault

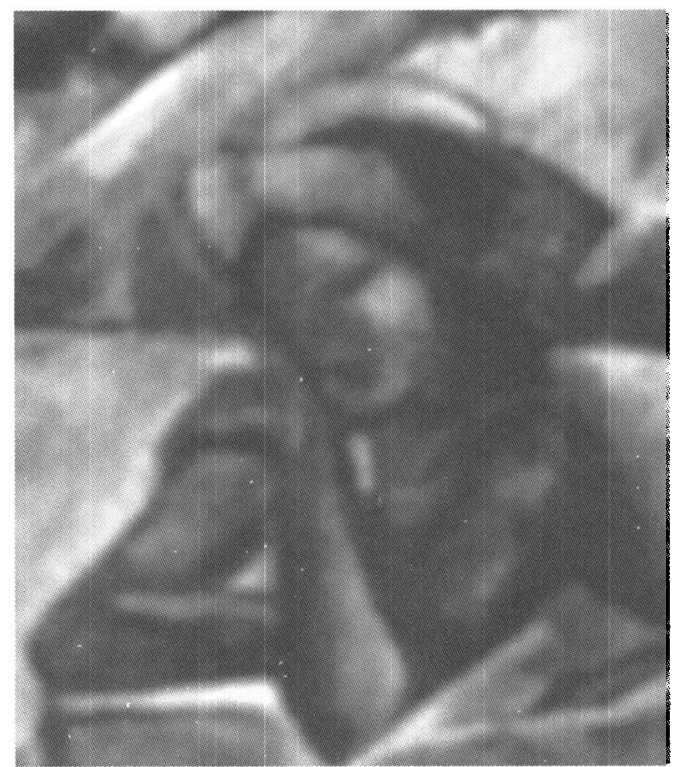

Foucault abre novas perspectivas para se entender a noçāo de posicionamento. Assim, para ele, o intelectual é "alguém que ocupa uma posiçāo específica" (1979: 13), de acordo com sua classe social, suas condições de vida e de trabalho e de acordo com "a política de verdade nas sociedades contemporâneas" (1979: 13). Esse "intelectual específico", que Foucault considera como substituindo o "intelectual universal" do começo do século, é chamado a assumir responsabilidades políticas, "quer queira, quer não", tornando cada vez mais importante a necessidade de se posicionar.
Foucault propõe que se pense os problemas políticos dos intelectuais em termos de "verdade e poder", ao invés de "ciência e ideologia". Para ele, "a verdade não existe fora do poder ou sem poder.... A verdade é deste mundo; ela é produzida nele graças a múltiplas coerções e nele produz efeitos regulamentados de poder(...) Há um combate "pela verdade" ou, ao menos, "em torno da verdade" (1979: 12-13). Foucault considera central o lugar da criatividade na vida. Em seminários realizados em Berkeley, em 1983, cerca de um ano antes de sua morte, ele se pergunta, inconformado, por que a vida de todo mundo não pode se transformar num trabalho de arte, como acontece com os objetos (1983: 236). E argumenta que temos que nos criar a nós mesmos como um objeto de arte, já que o eu não nos é dado.

Em seu belo artigo sobre "Saberes Localizados", Haraway também argumenta "a favor de políticas de alocação, posicionamento e situação nas quais parcialidade e não-universalidade são as condições para ser ouvido nas propostas a fazer do conhecimento racional" (1995: 38). Ela propõe que o conhecimento se desenvolva através de "conversas não inocentes", isto é, levando em consideração as relações de poder. E insiste que "[p]osicionar-se implica responsabilidade por nossas práticas capacitadoras. Em consequência a política e a ética são a base das lutas pela contestação a respeito do que pode ter vigência como conhecimento racional" (1995: 27-28). Haraway considera os objetos como tendo o estatuto de agente/ator e, portanto, as explicações em ciência "não dependem da lógica da 'descoberta', mas de uma relação social de 'conversa' carregada de poder. $\mathrm{O}$ mundo nem fala por si mesmo, nem desaparece em favor de um senhor decodificador" (1995: 37).

De modo a possibilitar um encontro menos atribulado com a diferença e a necessidade de se posicionar, a turma se divide em seis sub-grupos e prepara um seminário final, com base na leitura dos seguintes livros:

Beauvoir, S. de. (1949). O Segundo Sexo. São Paulo, Rio de Janeiro: Difel., Ciampa, A. (1987). A Estória do Severino e A História da Severina: Um ensaio de Psicologia Social, São Paulo: Brasiliense.Coimbra, C. (1995). Guardiães da Ordem: uma viagem pelas práticas psi no Brasil do "Milagre". Rio de Janeiro, Oficina do Autor.Lispector, C. (1978). A Hora da Estrela. Rio de Janeiro, José Olyimpio, 2a. edição. Reis Filho, J. T.. (2000). Ninguém atravessa o ArcoÍris: um estudo sobre negros. São Paulo, Belo Horizonte: Annablume, Newton Paiva. Silva, H. (1993). Travesti: a invenção do feminino. Rio de Janeiro: Relume Dumará, ISER. Souza, N. Santos. 
(1983). Tornar-se Negro ou As Vicissitudes da Identidade do Negro Brasileiro em Ascensão Social. Rio de Janeiro: Graal.

Todos esses livros tratam da questão da construção da identidade de grupos excluídos -mulheres, imigrantes nordestinos, travestis e negros. $\mathrm{O}$ livro de Cecília Coimbra trata da formação de profissionais em Psicologia na época da ditadura e como essa formação em grande parte compactuou com a produção de uma subjetivação hegemônica e supostamente apolítica. As apresentações dos seminários, bem como o que cada pessoa escreve sobre sua própria relação com o livro, são momentos importantes do grupo, onde podemos observar o envolvimento das pessoas e a abertura para a capacidade de se inquietar e se indignar, ou seja, para entrar em contato com as sensações.

\section{As Faladeiras}

Gostaria de terminar estas reflexões retornando a uma das experiências com que iniciei este ensaio -a experiência de fazermos juntas o cartaz na Delegacia convocando outras mulheres para o grupo. O cartaz foi uma colagem com figuras recortadas de revistas e a primeira figura foi escolhida pela mesma mulher que não quis deixar o beijo no cartaz porque achava seus lábios grossos demais. A figura era uma enorme boca de homem gritando: "Cala a boca incompetente!" Essa é a figura que fica bem no canto esquerdo superior, iniciando a mensagem do nosso cartaz. Quando viu a figura, a mulher comentou, "É assim que ele fala pra mim. É só ele que pode falar."

Nosso grupo fez um ano no dia 20 de abril de 2002 e comemoramos com um bolo de maçã, distribuindo a receita entre as pessoas que compareceram à festa, onde contávamos o que simbolizava o bolo e também nossa idéia de darmos um nome ao Grupo: As Faladeiras. Essa idéia tinha surgido na sessão do dia 8 de março, Dia Internacional da Mulher, quando homenageamos Camille Claudel por ela ter algumas esculturas que representam mulheres juntas em situações de aproximação. Les Bavardes é talvez sua escultura mais conhecida. São quatro mulheres sentadas, conversando, uma delas falando alguma coisa que as outras ouvem atentamente, as cabeças próximas, numa atitude de cumplicidade. A tradução do título em português é "As bisbilhoteiras", que não consideramos adequado, devido ao sentido pejorativo relacionado à intriga e fofoca. "Faladeira", por outro lado, é uma palavra que só existe no feminino em português (Novo Aurélio, Século $X X I$ ) -não existem "faladeiros" em nossa língua. E o sentido de "mulher que fala muito e fala com indiscrição" se aproxima bem mais do sentido de "bavarde" em francês, que significa "pessoa que conta com indiscrição" $\mathrm{e}$ "fala quando devia se calar" (Petit Robert 1).

Meu sonho de chegar com estudantes de Psicologia a uma herética heteroglossia envolve também aprender a lidar com as relaçōes de poder, como uma forma de combate à violência que facilmente irrompe em situações de desigualdade ou de hierarquia, como a relação entre professor/ a e estudantes. Para Arendt, o poder só existe em situações em que os sujeitos podem agir e podem falar" enquanto "a violência é muda ... tem início onde termina a fala" (1993: 40). De modo semelhante, Foucault considerava que, onde há poder, há sempre a possibilidade de resistência. Porém, à violência só se pode opor a passividade. A experiência de violência foi trazida pela mulher do nosso grupo tanto no momento em que se recusou a deixar sua marca no cartaz alegando que o formato de seus lábios não se adequava ao padrão/estereótipo como no momento em que escolneu a figura da boca masculina gritando "Cala a boca, incompetente!" se reportando à sua experiência com o marido em casa.

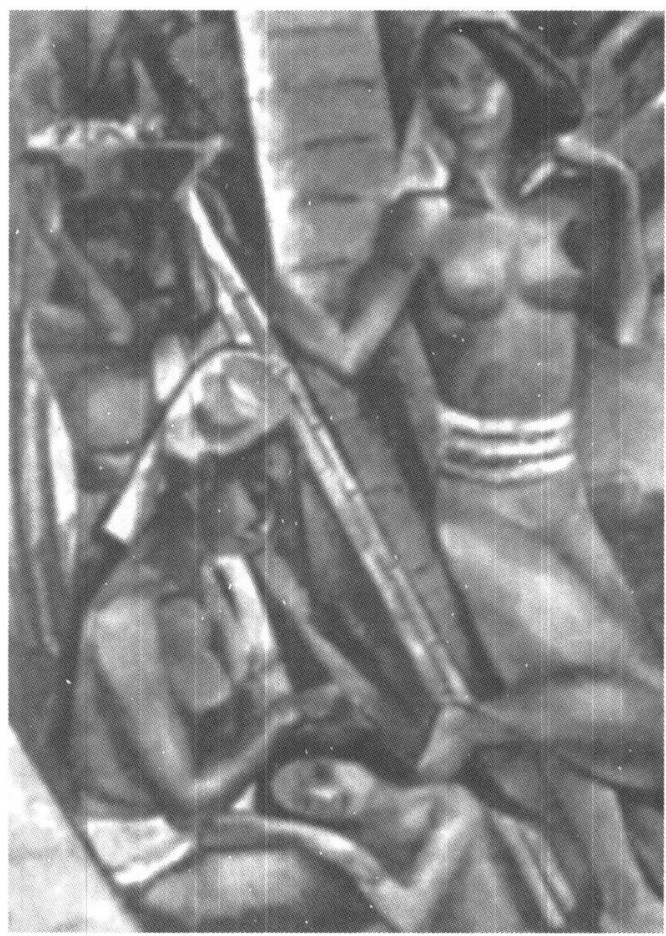
Meu sonho de
chegar com
estudantes de
Psicologia a uma
herética heteroglossia
envolve também
aprender a lidar com
as relações de poder,
como uma forma de combate à violência que facilmente irrompe em situaçóes de desigualdade ou de hierarquia, como a reiação entre professor/ae estudantes.

No mesmo relatório que escrevi para a turma 2/ 97, há um trecho de um relatório de observação de um/a estudante que exemplifica bem minha preocupação em estabelecer uma relação sem violência com as/os estudantes, respeitando nossa singularidade.

Uma aluna diz que já temos um estereótipo de professor. Este pode calar mais facilmente a boca 
dos alunos do que vice-versa. A professora diz que nós temos sempre que tentar mudar a situação, $\mathrm{e}$ isto não é ser radical nem dogmático. Um outro aluno diz que o estereótipo de radical está ligado à rigidez e a professora diz que é por isso mesmo que ela não quer tê-lo. $E$, após outros comentários, finaliza: "Não deixem que eu cale a boca de vocês."

Certamente, de alguma forma, posso estar calando a boca dos/as estudantes, mas o que importa é que continuemos nossa conversa não inocente sobre nossas relações de poder. Pois, conforme disse Roland Barthes em sua Aula,

“o poder (a libido dominandi) aí está, emboscado em todo e qualquer discurso, mesmo quando este parte de um lugar fora do poder. Assim, quanto mais livre for esse ensino, tanto mais será necessário indagar-se sob que condiçōes e segundo que operações o discurso pode despojar-se de todo desejo de agarrar (1997: 10).

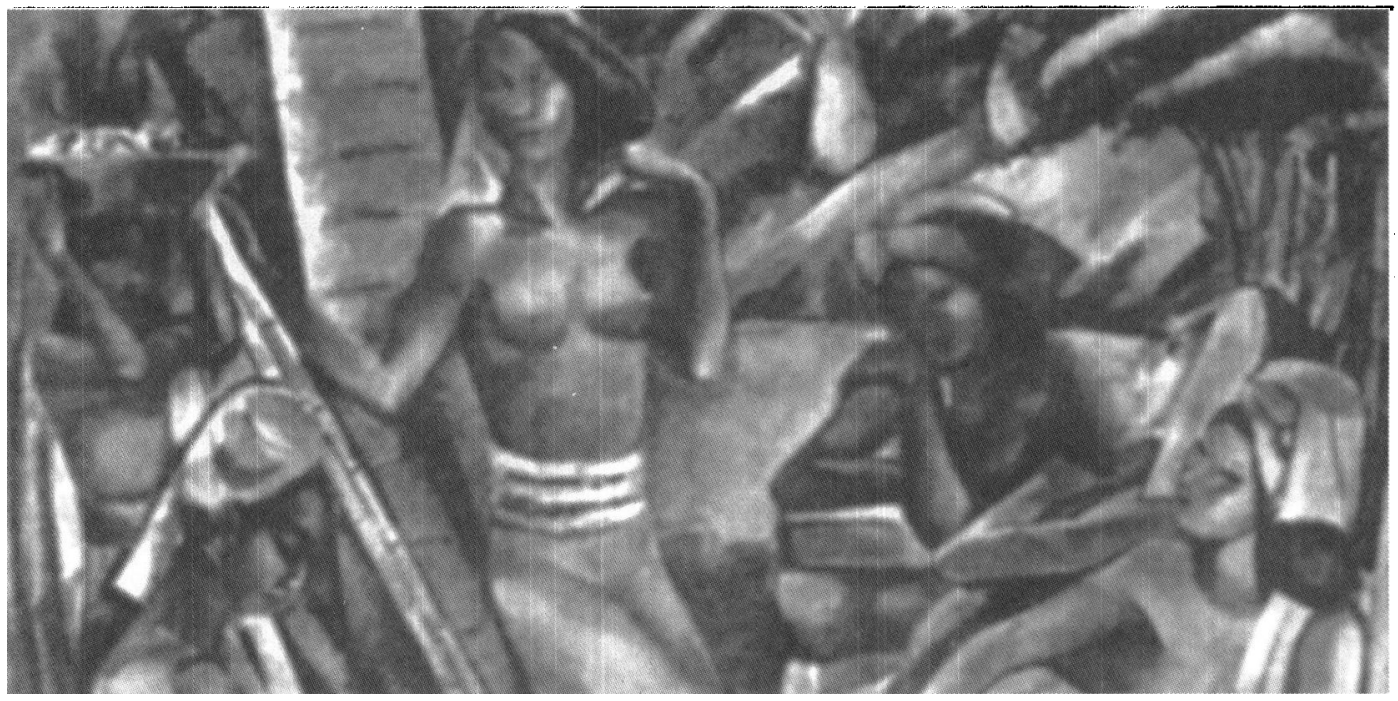


Sandra maria da Mata Azeredo

rua conde linhares, 1069-apt.1102

CEP: 30380-030 beto horizonte - MC Tel.: 31-32967110

E-mail: azeredo@fafich.ufmg.br

Recebido 02/05/02 Aprovado 16/08/02

Arendt, H. (1987). A Condição Humana. Trad. Roberto Raposo. Rio de Janeiro: Forense-Universitária.

(1993). A Dignidade da Política. Org. Antonio Abranches. Rio de Janeiro: Relume Dumará.

Azerêdo, S. e Santana, D.. (1997). Encontrando nosso "estranho outro": análise de uma experiência de grupo operativo em sala de aula. Cadernos de Psicologia da UFMG, vol. 7, no. 1, 155-166.

Azerêdo, S. (2001). O Significado da Violência de Cênero e a Questão da Demanda na Delegacia de Mulheres de Belo Horizonte, Caderno de Debates Plural, FCH - FUMEC, ano 10, no.15, março, 81-106.

Barthes, R. (1997). Aula. São Paulo: Cultrix.

Bauman, Zygmunt. (1998). O Malestar da Pós-Modernidade. Rio: Jorge Zahar.

Camino, L. (2001). A Face Oculta do Racismo. Psicologia Politica, ano 1, vol.1, no. 1,13-36.

Coimbra, C. (2001). Psicologia, Direitos Humanos e Neo-liberalismo. Psicologia Política, ano 1, vol.1, no. 1, 139-148.

Foucault, (1979). Microfisica do Poder. Trad. EOrg. Machado, Roberto. Rio de Janeiro: Graal.

(1983). Afterword: The Subject and Power. Em Dreyfus, - Hubert \& Rabinow, Paul, Michel Foucault: Beyond Structuralism and Hermeneutics (pp.208-226). Chicago: The University of Chicago Press.
Haraway, D. (1995). Saberes Localizados: a questão da ciência para o feminismo e o privilégio da perspectiva parcial. Trad. Mariza Correa. cadernos pagu, 5, 07-41

(2000). Manifesto ciborgue: ciência, tecnologia e feminismo socialista no final do século XX. IN Silva, Tomas Tadeu da, Antropologia do Ciborgue. Belo Horizonte: Autêntica.

Lane, S. (1989). O processo grupal. Em Lane, S. e Codo, W. (Orgs.) Psicologia Social: O homem em movimento (pp. 78-98). São Paulo: Brasiliense.

Mendonça, R. (2002). O paradoxo da Miséria. Veja, ano 35, no. 3, 23 de janeiro, 82-93.

Pichon-Rivière, E. (1994). OProcesso Grupal. São Paulo, Martins Fontes.

Reis Filho, 1. T.. (2000). Ninguém atravessa o Arco-íris: um estudo sobre negros. São Paulo, Belo Horizonte: Annablume, Newton Paiva

Rolnik, S. (1994). Cidadania e alteridade: o psicólogo, o homem da ética e a reinvenção da democracia, IN Spink, Mary Jane (org.), A Cidadania em Construção: Uma reflexão transdisciplinar. São Paulo: Cortez Editora

Rosaldo, M. (1995). O uso e o abuso da antropologia: reflexóes sobre o feminismo e o entendimento intercultural. Horizontes Antropológicos, ano 1, no. 1, 11-36.

Silva, M. P. (2001). O Anti-racismo no Brasil: Considerações sobre o estatuto social baseado na consciência racial. $P$ sicologia Politica, ano 1 , vol.1, no. 1, 37-65.

\section{Referências bibliográficas}

